\title{
UN TEXTO MÁS: LOS GRAFITI
}

\author{
Óscar Omar Yáñez \\ Liceo $N^{\circ} 18$ - Montevideo
}

\section{El grafiti en el proceso educativo}

Desde mi iniciación en la docencia, me he formulado propuestas de trabajo que colaboraran con mi tarea, fundamentalmente relacionadas con la motivación del educando y con el conocimiento de escritores de lengua española que construyen los esquemas básicos, en el aula, del estudio gramatical de nuestro idioma.

Asimismo, esta necesidad me ha conducido a socializar cada vez más el proceso educativo, porque, a partir del estudio en la clase de la realidad circundante, surge un estado de motivación real y espontánea que contribuye con el éxito de la tarea docente.

Esto significa que varios conceptos deben entablar relaciones recíprocas a la hora de la planificación: realidad social, arte y objetivos educativos.

El conocimiento del arte popular no permanece ajeno a las clases del Idioma Español y de Iniciación a la Literatura. Sin embargo, en esta oportunidad quiero conjugar dos conceptos: arte y calle. 
Arte, en cuanto al creador anónimo, ingenioso, picaresco, preocupado por sí mismo y por el hombre común o público que lo inspira y proyecta.

Calle, en cuanto a la pared o el muro que actúa como soporte textual para la transmisión de un pensamiento, una ocurrencia, etc...

Ante estos planteamientos nace de inmediato la idea del grafiti $^{1}$.

No soy un investigador. Soy un docente. Por lo tanto, no efectuaré un estudio del término ni una clasificación estrictamente científica de los contenidos afectados. Apenas deseo manifestar un interés por el estudio de un tema a sugerir su inclusión en el currículum de la enseñanza media, porque se trata de una forma real de comunicación que colabora notablemente en la motivación del estudiante y constituye una herramienta para incorporar ciertos instrumentos lingüísticos. El grafiti es un reflejo de las necesidades sociales y sicológicas de los alumnos.

\section{La experiencia}

Un docente de Idioma Español encuentra en el grafiti una fuente lingüística importante para el estudio de diversas estructuras gramaticales.

Ante esta alternativa, presenté a mis alumnos un conjunto de grafitis que, por diversos medios, llegaron a mí. Resultó evidente que el soporte textual (el pizarrón) era inadecuado. Decidí, entonces, acercar a los jóvenes al ámbito natural para reconocerlos, registrarlos y comentarlos. Visitamos dos espacios en los que los grafitis surgen con naturalidad, dada la constante afluencia de jóvenes: dos paredes del Liceo No. 18

1. Para la ejecución de este trabajo he optado por la unidad ortográfica grafiti. Materiales consultados y alumnos utilizan (para el singular): graffiti, grafitti, graffitti o grafiti. 
"Sarandí" y la galería exterior del Museo "Juan Manuel Blanes".

El impacto se produjo sin tardanza. Quizá por primera vez, aquellos fueron conscientes del contenido de estos textos, lo que les permitió consignarlos, juzgarlos, criticarlos y clasificarlos. Frente a tantas reacciones sólo me limité a recordarles que tal vez muchos de esos textos habían sido producidos por jóvenes como ellos y que, a partir de sus observaciones, elaboraran un concepto personal de grafiti.

No dudaron en la necesidad de trabajar y, de inmediato y durante una semana, los registraron. Simultáneamente, los clasificaron: "los de humor", "los de humor negro", "los obscenos" y "los de pensar".

En definitiva, comprobaron las capacidades de producir grafitis y de reconocerlos y comprenderlos. Comprensión y producción, dos fases ineludibles en el acto de enseñar lengua.

Entonces, el grafiti existe, pero ¿cómo definirlo?, ¿se puede definir el contenido del grafiti? Las respuestas son afirmativas. Recurriré a mis alumnos para demostrarlo.

\section{Definiciones de "grafiti"}

Presento algunas de las definiciones producidas por los alumnos de segundo año, las que sólo sufrieron algunas correcciones ortográficas, aunque mantengo la grafía del término definido según la elección de los estudiantes.

El grafiti es una forma de expresión escrita en una pared ya sea con el fin de hacer reir o de herir.

El grafiti es una forma de expresión escrita que se plasma en la pared (la mayoría de las veces). Puede reflejar diferentes

2. Me pareció oportuno mantener las designaciones creadas por los estudiantes. 
También importa el efecto que causa el grafiti en los lectores, en esta ocasión, los educandos. Para manifestar ese afecto, presento un conjunto de trabajos de producción escrita elaborados por mis alumnos. Los acerco a través de una - probablemente- incompleta clasificación, pero sí respetuosa, porque responde a las observaciones de los jóvenes mientras se recogía información:

\section{Grafitis}

de humor
de humor negro
obscenos
de pensar y desahogarse

En la siguiente muestra no aparecen los denominados "grafitis obscenos", p.orque los alumnos no los abordaron. Es probable que el trabajo en el aula y algunos tabúes con respecto al "lenguaje en clase" hayan incidido en esa decisión. Jamás duante esta propuesta de producción escrita hubo prohibiciones específicas. Además, la consigna del trabajo era muy clara: "Elija un grafiti, escríbalo y coméntelo".

Los grafitis de "humor"

Cuando desayuno pienso en ti y no puedo comer.

Cuando almuerzo pienso en ti y no puedo comer.

Cuando ceno pienso en ti y no puedo comer.

Cuando me acuesto no puedo dormir

porque estoy muerto de hambre.

Comentario:

Yo pienso que este grafiti nos trata de transmitir alegría; este grafiti empieza como si estuviera dirigido con amor hacia alguien pero termina una fachada humorística.

Conclusión: quien lo haya pensado relacionó o mezcló amor con humor. 
El pan no engorda, engorda el que lo come.

Comentario:

Yo creo que este grafiti es bastante ingenioso. Porque mucha gente dice el pan engorda y no es cierto. Porque el que va a engordar va a ser la persona que lo coma, no el pan por sí solo. Asi que creo que es un grafiti que intenta reflejar la realidad, que muchas veces nos expresamos mal y este grafiti: trata de corregirlo.

El palacio legislativo sirve para algo.

(las palomas)

Comentario:

Este grafitti está expresando por el emisor un rechazo hacia la política, forma política, gobierno, cámaras, etc.

Este rechazo o desprecio se lo transmite al receptor, que lo puede tomar humorísticamente, que mi forma de pensar, lo tiene por su originalidad y sin necesidad de ese humor negro que puede lastimar los pensamientos de algunas personas por ej.: Al principio está frío y después te acostumbras (A.Storni).

Grafitis de "humor negro"

Para reunir a los Beatles hacen falta tres disparos más.

Comentario:

Es un grafiti que contiene netamente humor negro. Con este se puede herir a muchas persónas, porque como John Lennon fue asesinado a balazos para reunir nuevamente a los Beatles habría que asesinar a los tres restantes.

Al principio está fría, pero después te acostumbrás.

(A. Storni) 
Comentario:

En el grafiti predomina el sarcasmo que es lo fundamental en este grafiti. También tiene mucho de humor negro. En general es un buen grafiti porque está bien ideado al tomar del rabo a la muerte de una personalidad tan grande como fué A. Storni. Es una realidad como casi todos los grafitis.

Grafitis "de pensar"

Quien nunca cometió un herror jamás descubrió nada.

Comentario:

Este grafiti expresa en su contenido un pensamiento, que te produce una reflexión: que un herror no lo es todo y que se puede superar y sobre él descubrir que ese mismo herror no se va a volver a cometer. Y hací llegar a lo que cada uno se proponga.

Cuando hables con un imbécil asegurate de que el no este haciendo lo mismo.

Comentario:

A mí esto me ha pasado. Yo consideraba a esa persona imbécil y quizá la imbécil era yo. Creo que trata de expresar que uno no debe subestimar a esa persona ni ponerle calificativos, menos aun si no lo conocemos porque puede resultar lo contrario.
Al amigo no lo busques perfecto búscalo amigo

Comentario:

Este grafiti quiere comunicar que no nos tenemos que fijar en la parte exterior de las personas sino en la interior. 
Comentario:

En el grafiti predomina el sarcasmo que es lo fundamental en este grafiti. También tiene mucho de humor negro. En general es un buen grafiti porque está bien ideado al tomar del rabo a la muerte de una personalidad tan grande como fué $\mathrm{A}$. Storni. Es una realidad como casi todos los grafitis.

Grafitis "de pensar"

Quien nunca cometió un herror jamás descubrió nada.

Comentario:

Este grafiti expresa en su contenido un pensamiento, que te produce una reflexión: que un herror no lo es todo y que se puede superar y sobre él descubrir que ese mismo herror no se va a volver a cometer. Y hací llegar a lo que cada uno se proponga.

Cuando hables con un imbécil asegurate de que el no este haciendo lo mismo.

Comentario:

A mí esto me ha pasado. Yo consideraba a esa persona imbécil y quizá la imbécil era yo. Creo que trata de expresar que uno no debe subestimar a esa persona ni ponerle calificativos, menos aun si no lo conocemos porque puede resultar lo contrario.

Al amigo no lo busques perfecto búscalo amigo

Comentario:

Este grafiti quiere comunicar que no nos tenemos que fijar en la parte exterior de las personas sino en la interior. 
No hay que mirar si es lindo, si es feo, si es alto, si es bajo, si es gordo, etc..

Nos tenemos que fijar si está al lado de nosotros en los momentos buenos y en los malos, si nos da una palabra de aliento y si nos necesita también.

Además un amigo se puede equivocar y cometer errores, puede ser injusto en muchas ocasiones pero como todo ser humano: nadie es perfecto.

\section{Conclusión}

La propuesta está formulada. Queda en nuestras manos apovechar u olvidar una exquisita forma de comunicación que no nació en nuestro medio pero que en él se ha arraigado.

Se trata de un tema que compromete a docentes y a todos quienes tengan un contacto directo con las relaciones humanas. Como este compromiso podría resultar demasiado ambicioso, considero que el docente de lengua es quien debería propiciar el estudio de este tipo de texto y, sobre todo, promover su observación como un modelo lingüístico que, por pertenecer a los jóvenes y conocer la amplitud del destinatario, facilita el abordaje no sólo desde el punto de vista semántico, sino también desde el punto de vista pragmático.

En tal sentido, es interesante observar el manejo del espacio y el uso de marcas lingüísticas con intención pragmática. Esto nos indica que la lengua, tan compleja y completa, y estricta ante el uso de ciertos instrumentos, es insuficiente para transmitir, en ocasiones, el sentimiento o el pensamiento del hombre que se desarrolla como el autor de un grafiti. Por eso, éste combina todas las posibilidades lingüísticas, paralingüísticas y espaciales para obtener su producto textual.

Una clase de lengua se organiza a partir de la presentación de modelos lingüísticos que satisfagan las necesidades e intereses de los alumnos. Gracias a esa presentación e identificación de modelos, el alumno accederá a la etapa de produc- 
ción y, simultánea o consecuentemente, desarrollará el placer por la lectura. ¿Qué efectos podrá producir la presentación del grafiti en aquellas aulas en donde sólo el texto literario constituye una obra de arte? ¿Esos efectos serán sólo de índole educativa?

Lo cierto es que estos textos constituyen un excelente motivo parà trabajar en clase tanto la oralidad como la escritura. Además, socializan el proceso de enseñanza-aprendizaje porque la tarea en grupo permite el intercambio y el descubrimiento de ambiciosas formas comunicativas.

Para finalizar, me pregunto si ese uso de lo lingüístico y lo no lingüístico que redunda en un grafiti se manifiesta, sin intención previa, en otras producciones de texto. Tal vez los docentes no nos detuvimos a observar. ¿La deficiencia en la producción de textos de los estudiantes será realmente deficiente o estaremos asistiendo a un cambio profundo en la modalidad expresiva que aún no aceptamos o advertimos? ¿Acaso, uno de los secretos del éxito en la enseñanza de la lengua materna se halla en la capacidad de transferir, paulatinamente, el análisis de modelos vividos por o integrados al educando a productos -más o menos- desconocidos o complejos? 